\title{
Software, dado e algoritmo como formas culturais na Netflix
}

\section{Kélliana Braghini}

Mestra; Universidade do Vale do Rio dos Sinos Unisinos, São Leopoldo, RS, Brasil

kellianaaa@gmail.com

\section{Sonia Montaño}

Doutora; Universidade do Vale do Rio dos Sinos, São Leopoldo, RS, Brasil

soniamontano@gmail.com

\section{Resumo}

O audiovisual contemporâneo - principalmente o que circula em plataformas de vídeo na web - exige olhar para além das narrativas, à medida que se insere em ambientes mediados por softwares, tornando-se, ao mesmo tempo, produto e produtor de bancos de dados geridos por algoritmos. Pretendemos, neste artigo, compreender como os bancos de dados e os algoritmos constituem-se em formas culturais e de que maneira impactam, particularmente, o modo em que o audiovisual da Netflix se enuncia. Para isso, articulamos a metodologia das molduras e os pressupostos de autores que abordam as mídias na perspectiva tecnocultural, como McLuhan, Manovich, Flusser e Chun.

\section{Palavras-chave}

Software. Dados. Algoritmos. Formas culturais. Netflix.

\section{Introdução}

Durante muito tempo, a narrativa era a forma cultural preponderante para olhar as mídias audiovisuais - inclusive, para direcionar as metodologias de análise e as abordagens acadêmicas. Nesse sentido, o audiovisual contemporâneo, principalmente o que circula em plataformas gratuitas ou pagas, de produção amadora ou profissional, torna-se um desafio para a pesquisa acadêmica. Muitas dessas abordagens são conteudísticas, visando apenas o aspecto narrativo de filmes ou séries. Entretanto, cada vez mais são demandados outros 
olhares para compreender tais mídias audiovisuais, em suas relações técnicas, estéticas e culturais. As mídias, suas formas de produção e compartilhamento com toda sua complexidade, as tecnoculturas nas quais nascem e os modos de produção de sentido que nelas se organizam: ao final o que eles estão dizendo sobre o audiovisual? É com esse objetivo que olhamos, neste artigo, para a plataforma da Netflix.

A Netflix se afirma como uma das líderes de serviço digital desde 1997, ao lançar-se no mercado como locadora de vídeo pela internet. Fundada por Reed Hastings e Marc Randolph, em Los Gatos, Califórnia (EUA), a empresa oferecia, por meio do site Netflix.com, um acervo de DVDs, disponíveis para compra e aluguel apenas no território estadunidense. Em 1999, passou a promover assinaturas, oferecendo locação ilimitada de filmes por um valor mensal. 0 assinante solicitava o que queria ver e recebia em casa, por correio, sem data limite para a devolução.

Somente em 2007, a plataforma de transmissão online foi criada, permitindo o acesso a conteúdo instantâneo e sob a demanda no computador. Por meio de parcerias com fabricantes eletrônicos, as formas de acesso foram expandidas para múltiplas telas ${ }^{1}$. Até então, o acesso só estava disponível para clientes nos EUA. Em 2010, passou a ofertar o serviço no Canadá e, no ano seguinte, chegou à América Latina, até se expandir para praticamente todo o mundo em 2016. Hoje, a Netflix possui 104 milhões de assinantes em mais de 190 países.

Definida no centro de ajuda do site como “[...] um serviço de transmissão online que permite aos clientes assistir a uma ampla variedade de séries de TV, filmes e documentários premiados em milhares de aparelhos conectados à internet." (NETFLIX, 2018, doc. não paginado), a Netflix sintetiza um dos modos como dá significados a si própria. Faremos, ao longo desta reflexão, uma travessia pela Netflix a partir da metodologia das molduras (KILPP, 2003, 2010), com o objetivo de perceber os sentidos dados ao audiovisual e à própria plataforma nas suas interfaces gráficas, e tentaremos perceber junto a um conjunto de autores que sentidos são esses que essa mídia em particular constrói para si e para o audiovisual contemporâneo.

\footnotetext{
10 acesso à Netflix está disponível em pelo menos sete aparelhos: nas Smart TVs, aparelhos de transmissão-streaming, videogames, decodificadores de TV, aparelhos de Blu-Ray, smartphones e tablets, notebooks e PCs.
} 


\section{Princípios teórico-metodológicos}

Diante do desafio metodológico que as mídias contemporâneas, cada vez mais complexas, apresentam, consideramos importante apresentar a metodologia das molduras que inclui outras metodologias como um processo para a desconstrução do audiovisual. A metodologia é, conforme Kilpp (2010, p. 26), “[...] um conjunto de procedimentos de análise de audiovisualidades [...]" que articula intuição, cartografias, desconstrução e dissecação. Tratam-se de procedimentos de ordem técnica que des-discretizam digitalmente a imagem audiovisual - neste caso, as interfaces da Netflix.

Ao intervir nos materiais empíricos, a metodologia dá a ver as montagens, os enquadramentos e os efeitos discretos que não têm sentido nas imagens, mas que são praticados para produzir sentidos, e, no fluxo dessa mídia, passam a ter sentidos discretos e eficientes. Kilpp (2003) elencou quadros e territórios de experiência e de significação que se revelam decisivas para os sentidos que serão atribuídos a uma e a outra enunciação (significação). A metodologia, inicialmente pensada para televisão, mostrou-se eficiente para pensar como ela engendra mundos televisivos com características próprias e já foi largamente usada para os estudos da internet por autores como Montaño (2012), Bittencourt (2007) e Cardoso (2016).

A metodologia de Kilpp é desenvolvida a partir de três eixos conceituais: 1) o eixo das ethicidades; 2) o eixo das molduras moldurações e emolduramentos e 3) o eixo dos imaginários. Tentamos aqui cartografar algumas das molduras (territórios de significação) e das moldurações (procedimentos técnicos e estéticos) mais implicadas na enunciação de ethicidades (construtos do mundo: seres, durações, acontecimentos, que as imagens técnicas dão a ver como tais, mas, na verdade, são conceitos do mundo, técnica, estética e eticamente construídos). As molduras e as ethicidades devem ser pensadas juntamente com os imaginários audiovisuais e confrontá-lo com outros imaginários de mundo, “[...] pois, se há comunicação, é justamente porque esses imaginários são minimamente compartilhados." (KILPP, 2010, p. 21).

Para conseguir desconstruir os sentidos dados nas molduras, as diversas ethicidades e os diversos imaginários convocados, recomenda-se o procedimento técnico de dissecação das imagens. "Para descobrir essa quase-gramática é preciso um esforço de desencantamento [...]. É preciso desnaturalizá-las, retirá-las do fluxo de suas vagas, e dissecá-las em melhor estilo de Leonardo da Vinci." (KILPP, 2010, p. 87). Tais 
procedimentos teórico-metodológicos, embora nem sempre apareçam claramente descritos, acompanham o modo como a Netflix é pensada a seguir que é resultado do diálogo entre as autoras e suas respectivas pesquisas.

Dentro dos procedimentos da metodologia das molduras está a cartografia, um princípio pensado, aqui, a partir da figura do flâneur em Benjamin (2006). 0 andar pela cidade levava a Benjamin a familiarizar o estranho e a se distanciar do familiar pensado em outras relações contemporâneas nas quais coalescem tempos passados. Ao tornar todas as ruas íngremes, conduz o flâneur em direção a um tempo que desapareceu:

\begin{abstract}
Uma embriaguez apodera-se daquele que, por um longo tempo, caminha a esmo pelas ruas. A cada passo, o andar adquire um poder crescente; as seduções das lojas, dos bistrôs e das mulheres sorridentes vão diminuindo, cada vez mais irresistível torna-se o magnetismo da próxima esquina, de uma longínqua massa de folhagem, de um nome de rua. Então chega a fome. Ele nem quer saber das mil e uma possibilidades de saciá-la. Como um animal ascético, vagueia por bairros desconhecidos até desmaiar de exaustão em seu quarto, que o recebe estranho e frio. (BENJAMIN, 2006, p. 462).
\end{abstract}

Assim, tentamos transformar as ruas da Netflix em íngremes para percorre-las com o leitor e ir encontrando molduras e territórios discretos que se tornam fundamentais para entender os sentidos identitários da plataforma. A dissecação dessas imagens nos permite desconstruir e dar a ver as montagens e sobreposições que constroem esses sentidos deixando a própria natureza do meio na opacidade.

\title{
3 Acesso ao universo audiovisual
}

A partir, então, desta metodologia, convidamos os leitores a flanar conosco pelas primeiras páginas da Netflix, a fim de irmos acessando juntos estes territórios de significação nas interfaces e percebendo alguns dos sentidos ali propostos. 0 que apresentamos aqui, portanto, consiste em uma cartografia das páginas iniciais da plataforma, acessadas a partir da URL, em que colecionamos e dissecamos telas que nos pareceram importantes para dar a ver algumas molduras e ethicidades presentes na interface. Nestas interfaces, observamos uma coleção de itens audiovisuais armazenados e redistribuídos na plataforma, independentemente de serem oriundas do cinema, da TV ou feitas para internet. A página inicial leva a decodificar alguns caminhos que, no mínimo, tensionam a acessibilidade do usuário que lê na plataforma: "O assinante Netflix pode 
assistir a quantos filmes e séries quiser, quando e onde quiser, em praticamente qualquer tela com conexão à Internet. 0 assinante pode assistir, pausar e voltar a assistir a um título sem comerciais e sem compromisso." (NETFLIX INVESTORS, 2018, tradução nossa, doc. não paginado).

A primeira página que se desvela ao digitar a URL (Figura 1) explicita diversos construtos que são centrais para a plataforma: destacam-se aqui o usuário e o audiovisual. Em destaque, na Figura 1, a legenda em inglês (a única frase que não está na língua do país)², na parte superior esquerda da tela e em letra maior que todas as outras inscrições, - "See what's next" - moldura toda a página. O next (literalmente seria próximo/a ou seguinte) está moldurado de muitas formas na Netflix: desde as formas de disposição das listas dos vídeos até a passagem automática de um episódio para o seguinte. Trata-se de uma moldura muito presente, também, na cultura do binge-watching ${ }^{3}$ - outra ethicidade fortemente significada na Netflix. Por outro lado, o termo Next tem muita proximidade com a "Net", um modo de chamar a internet, que é a base do nome da Netflix (filmes na internet). Pensando neste panorama de molduras elencadas até aqui, o audiovisual da Netflix mostra-se como um audiovisual conectado, em rede, que sempre apresentará inesgotavelmente um próximo.

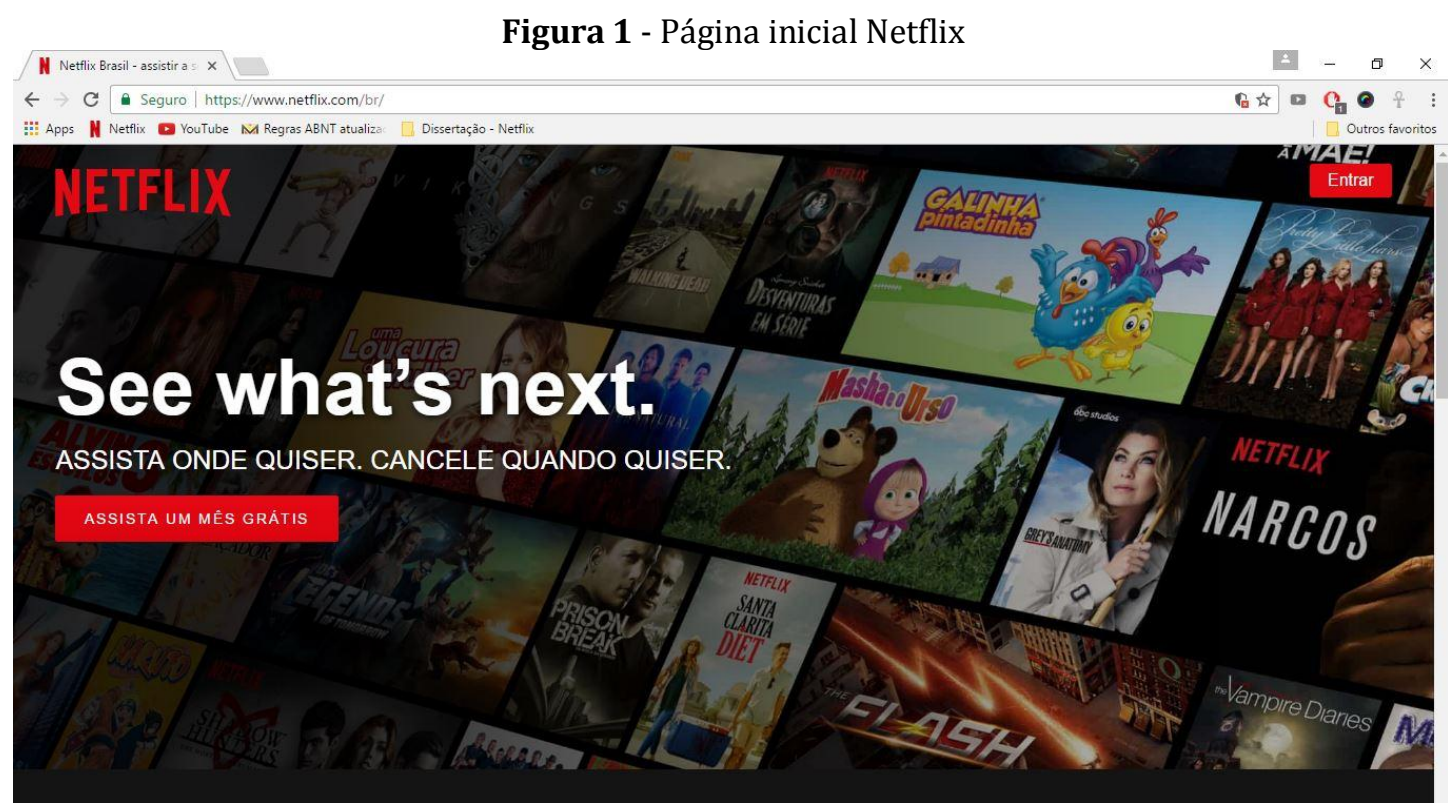

Fonte: Netflix (2017).

\footnotetext{
${ }^{2}$ A frase estava em inglês no momento da produção do artigo. Atualmente ao acessar a página lemos a frase "Sua próxima história, agora".

${ }^{3}$ Ato de ver vários episódios de uma série, sem intervalos.
} 
Ainda na página inicial, observamos que a interface (Figura 1) exibe um conjunto de imagens de conteúdos que lembram os cartazes que anunciam filmes cinematográficos nas entradas dos cinemas. Alguns são cortados pelas bordas da tela, sugerindo que a quantidade continua fora de campo (mas dentro da Netflix!) e se torna infinita. Os cartazes estão colados, sem aparentes interstícios que permitam operar (sobre eles não há links, não há reação ao passar do mouse).

Os cartazes estão em posição oblíqua e parecem seguir certo movimento que, embora alinhado, sinaliza uma relação de desenquadramento com a tela do dispositivo. No mínimo, torna-se difícil assistir a algum filme nessa posição de desconforto, sem ter que fazer algum tipo de movimento. Contudo, a interface indica que movimento deve ser esse nas duas únicas molduras, que têm fundo vermelho na tela: "assista um mês grátis" ou "entrar". Trata-se de dois caminhos moldurados como acesso (por links), em que são dados sentidos identitários diferentes ao usuário. Dessa forma a interface vai moldurando alguns caminhos para o usuário, a partir de alguns sentidos dados a si própria e seus modos de acesso.

No lado superior direito, que seria o espaço nobre, conforme nossa cultura da escrita, há o link "entrar", essa "porta" é para quem já "é de casa”, já percorreu o caminho de entrada previamente, mas, por alguma razão saiu do seu login da plataforma. Ao clicar, abre uma pequena janela para introduzir login e senha ou acessar com os dados do Facebook (Figura 2). Como plano de fundo está a imagem da série The Crown, o maior investimento em ficção seriada da Netflix (REDAÇÃO ELLE, 2016). Agora, há uma dimensão de intimidade do usuário com a plataforma: ele está muito próximo de acessar o conteúdo audiovisual exclusivo para assinantes, só falta inserir e-mail e senha. 0 que queremos destacar aqui é como há um sentido de familiaridade e acesso rápido às produções dado ao usuário que já tem login e um sentido de estranho ou estrangeiro dado ao usuário que não realizou seu cadastro. 
Figura 2 - Página de login

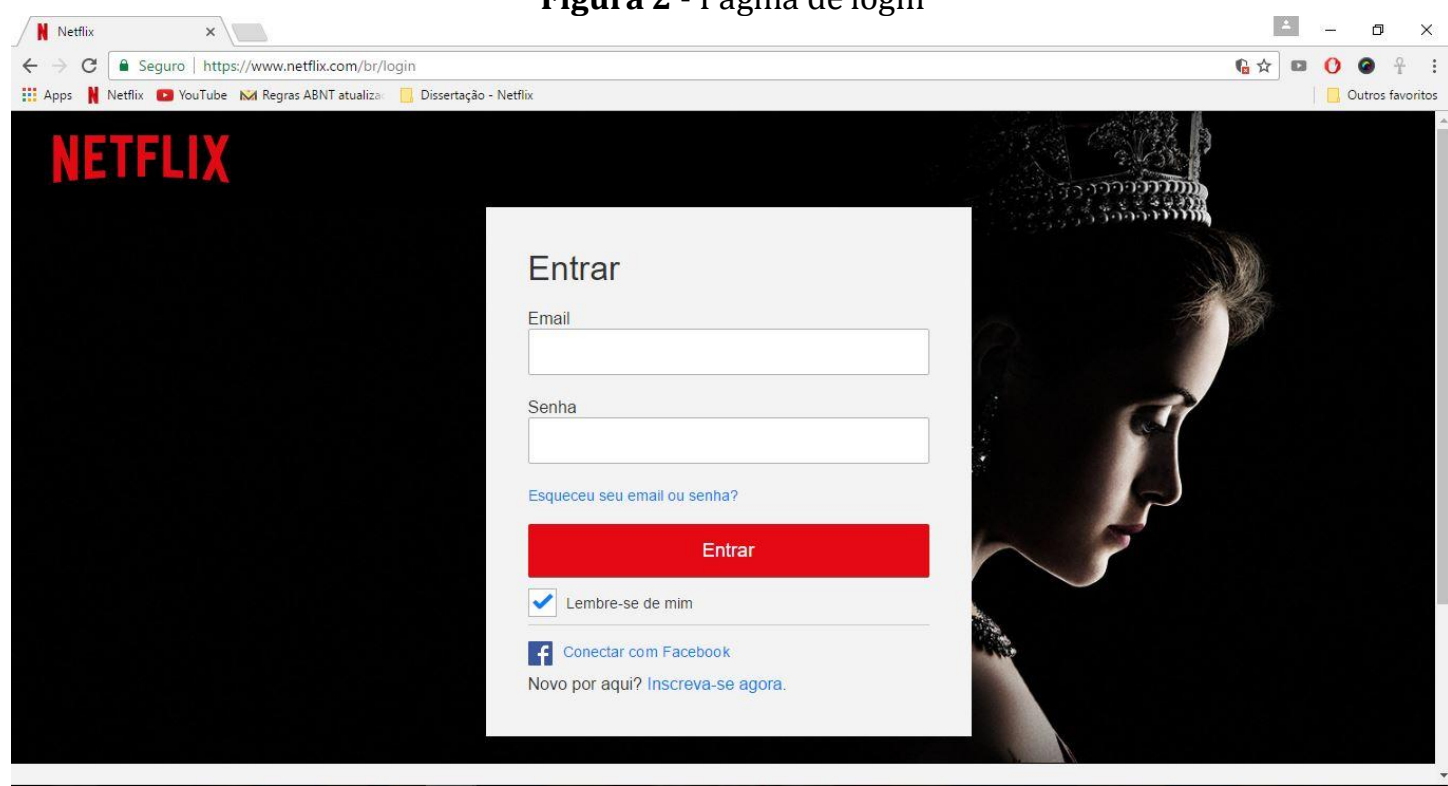

Fonte: Netflix (2017).

O usuário que já é assinante não está mais diante do caleidoscópio de produções ou de um conjunto sem acesso, mas, frente a frente com uma produção Original Netflix que, de certa forma, está sendo moldurada como a mais cobiçada ou recente. Voltando à página inicial e à situação daquele usuário que ainda não fez seu registro na Netflix, ao desconforto do desenquadramento é apresentada uma possibilidade: "assista um mês grátis". Esta outra moldura, também está em destaque à esquerda da tela (Figura 1), abaixo dos títulos. Ao clicar no link, o usuário é conduzido à página de fundo cinza (Figura 3), sem imagens, com apenas gráficos, letras e números que explicam os planos disponíveis, as vantagens e os custos. Aqui, o design lembra mais uma negociação, uma compra-e-venda, uma operação de ordem administrativa, sem o colorido mundo audiovisual próprio da maior parte das interfaces, mas ainda assim um universo amigável, com fundo cinza e um gráfico simplificado das vantagens de cada plano. 
Figura 3 - Escolha do plano

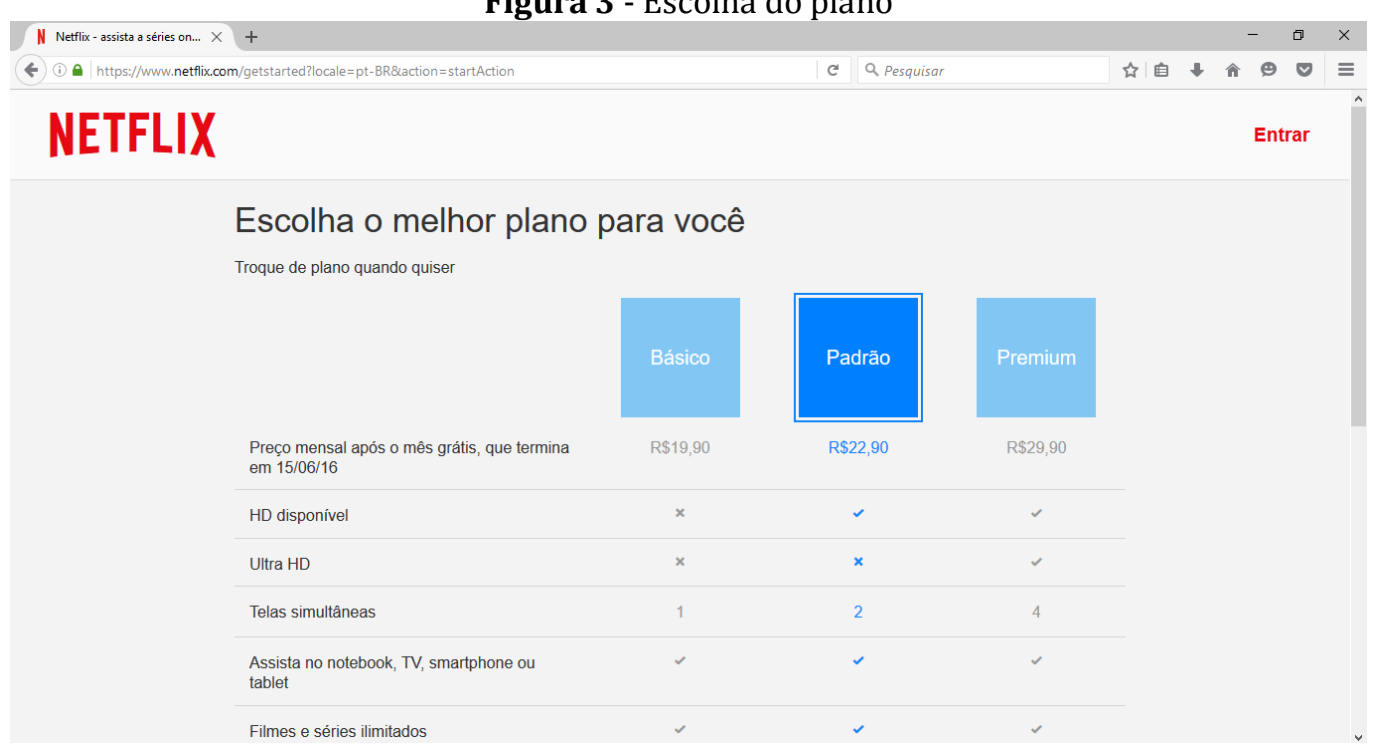

Fonte: Netflix (2017).

Como comentado anteriormente, é clara a delimitação de territórios diferentes que molduram o usuário ainda "estrangeiro" e o assinante. 0 mês grátis é concedido após o preenchimento da escolha de plano, dos dados pessoais e do cartão de crédito. 0 acesso ao universo audiovisual não é exatamente "como quiser" e "quando quiser", à diferença de outras plataformas, como o YouTube, em que vídeos ficam acessíveis sem fazer login. Nesse caso, as produções só serão acessíveis como um troféu após os dados do usuário e de seu cartão, juntamente com a aceitação dos termos, forem efetuados. 0 que nos leva a pensar o quanto o cartão de crédito é parte central da construção do usuário que transita pela plataforma e isso não é uma prática exclusiva da Netflix. As interfaces iniciais da Netflix, então, nos mostram sentidos dados na plataforma ao usuário, ao universo audiovisual e à relação entre ambos que se apresenta nos procedimentos de acesso. Dependendo do que acontecer na página inicial (preenchimento ou não de dados, inclusive cartão de créditos e email válido), o usuário será felizmente acolhido ou não passará daquela página.

o usuário que finalmente "entrou" (Figura 4) é ressignificado na página. É moldurado como alguém de casa, para quem o universo audiovisual fica aberto e disponível (embora nunca totalmente, só em termos de produção de sentido). Quando o usuário insere seu login e senha, há um território no qual ele é claramente enunciado como "dentro", como um habitante do que seria propriamente o universo Netflix. 0 conjunto de títulos já não está mais de forma oblíqua, apresentam-se em uma interface que relaciona usuário e imagens de filmes e seriados de modo organizado. As imagens não aparecem mais como meros cartazes 
na porta de um cinema ou em uma opção de desenquadramento nas relações entre usuário e tela. De alguma forma, essa nova molduração recicla imaginários das "velhas" videolocadoras, com corredores entre os quais caminhamos, manuseamos e lemos, no verso do vídeo, uma explicação antes de decidir levá-lo (ela aparece ao apoiar o mouse nas imagens).

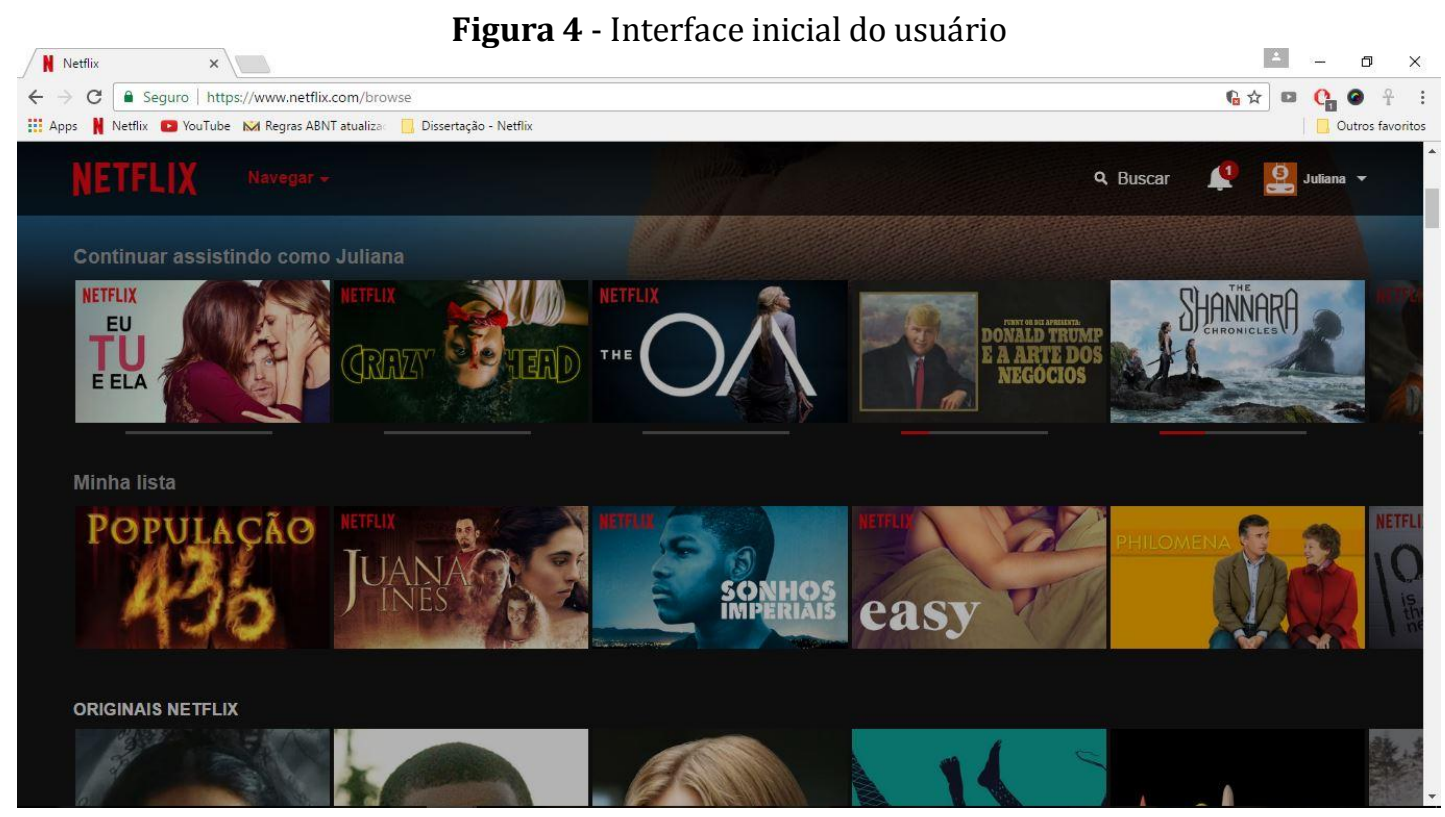

Fonte: Netflix (2017).

\section{0 usuário e o gênero como algoritmo na Netflix}

Uma questão chama a atenção do flâneur aqui: os corredores não obedecem aos clássicos gêneros, são formados por combinações que aliam tema, natureza, elenco e outras características de cada audiovisual. Convivem na interface gráfica do usuário, todos os gêneros tradicionais já consagrados anteriormente pelo cinema e pela TV, mas classificados e redistribuídos de outras tantas maneiras inimagináveis, reciclando diversos imaginários na tentativa de dar maior especificidade às produções. Neste caso, os algoritmos trabalham para atender à demanda de mais de 109 milhões de assinantes podendo atingir mais de 500 milhões de perfis diferentes; essa organização tão específica das categorias, bem como, quais títulos compõem cada linha e em que ordem, baseia-se nos dados de todos esses usuários. Existem mais de 76 mil combinações que formam categorias únicas de filmes e 
séries na Netflix. Todas elas estão no banco de dados da plataforma, mas apenas algumas estão visíveis na interface inicial e rotam a cada acesso. Todas essas categorias foram compiladas e listadas por um site americano que descreve de que forma são organizadas:

\begin{abstract}
Alexis Madrigal conta como Todd Yellin, vice-presidente do Netflix, criou uma "teoria quântica" para classificar os filmes e séries oferecidos pelo serviço. Basicamente, cada título recebe - manualmente! - uma anotação sobre seu conteúdo (romântico, violento, assustador etc.), sobre seu final (feliz, triste ou ambíguo), local, período em que a história se passa, os empregos dos principais personagens... tudo. A partir daí um algoritmo criado pelos engenheiros do Netflix gera as categorias malucas que o serviço oferece. Ou seja, obviamente há um elemento artificial; mas ele combina algo decidido por humanos. Por fim, o Netflix reúne as tags dos títulos que você assiste - e dos que você mais gosta - para assim recomendar filmes e séries. (VENTURA, 2014, doc. não paginado).
\end{abstract}

Destacamos aqui como a lógica de banco de dados atravessa tanto o elemento "humano" como o elemento "artificial" e o trajeto dos usuários, um grande universo movido a tags. 0 afunilamento de especificidades feito pelo algoritmo, por vezes, gera categorias extremamente particulares que provocam certo estranhamento, como o que vemos na Figura 5. 0 algoritmo processa informações das produções, usuários, interfaces e dados gerados pelo usuário.

Figura 5 - Dramas obscuros dos EUA para TV com mulheres fortes

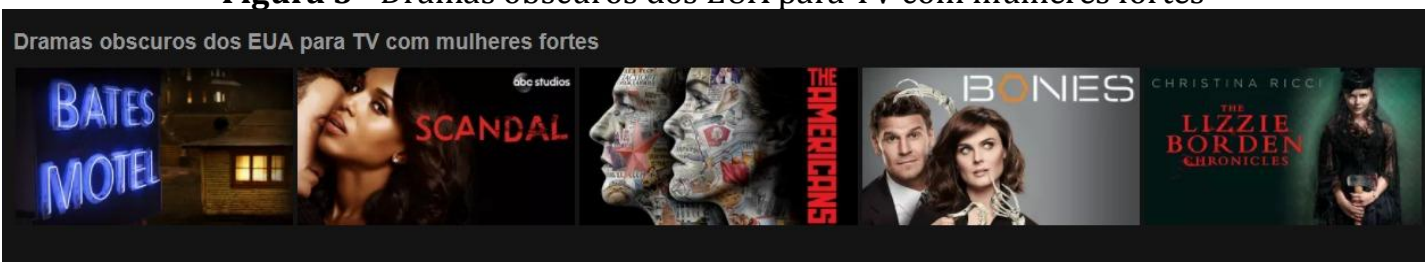

Fonte: Netflix (2017)

Existem categorias oficiais que se mantêm independentemente do perfil com que se está navegando como "Originais Netflix" e "Adicionados recentemente". Outros "gêneros" que agrupam os títulos nos corredores são personalizados e estariam fazendo leituras dos dados gerados pelo percurso do usuário como "Porque você assistiu a tal título" ou "Porque você adicionou tal título à 'Minha lista'”. Mais uma coleção formada pelos dados produzidos pelo usuário computados pelo algoritmo. Ainda que muitas dessas categorias sejam vistas em diferentes perfis, a ordem em que elas vão aparecer na interface, quais títulos estarão em cada uma delas, quais vídeos aparecerão primeiro e a imagem de divulgação desses 
títulos, nunca irá se repetir. Cada página inicial apresenta, aproximadamente, 40 linhas (ou categorias), cada uma delas com cerca de 80 vídeos (ou títulos) que se propõe a ser "personalizados". Embora, haja um padrão na distribuição de elementos na interface e, por isso, imageticamente todas as páginas iniciais, independente do usuário, se parecem, cada produção é disposta em um espaço específico para cada usuário com base na leitura feita pelo sistema de recomendações da Netflix.

Inicialmente, o mecanismo usado pela empresa, para coletar informações sobre as preferências dos usuários, eram as classificações por estrelas. Cada vídeo tinha um espaço que mostrava uma escala de uma a cinco estrelas parcialmente ou totalmente coloridas em amarelo. Quanto maior a quantidade de estrelas amarelas, maior a relevância daquele conteúdo para o usuário. Além de já possuir uma avaliação prévia, o usuário poderia sobrepor, com sua própria avaliação, dando de uma à cinco estrelas para cada produção (clicando sobre elas e, assim, colorindo-as em vermelho), demonstrando sua satisfação ou insatisfação. A leitura desses dados possibilitava a geração de notas para produções consideradas semelhantes ao que o usuário assistiu e avaliou (bem ou mal). Em 2016, o sistema de avaliação mudou para um modo com apenas duas opções: gostei ou não gostei. As ações são representadas por um ícone de polegar voltado para cima e outro para baixo, culturalmente identificados como símbolos de positivo e negativo. Estima-se que a precisão dessa e outras faces de leitura de dados sejam cada vez maiores, já que conforme a empresa:

Agora, transmitimos o conteúdo e temos uma grande quantidade de dados que descrevem o que cada membro da Netflix observa como cada membro observa (por exemplo, o dispositivo, a hora do dia, o dia da semana, a intensidade da exibição), o lugar em nosso produto em que cada vídeo foi descoberto e até as recomendações que foram mostradas, mas não assistidas em cada sessão. (GOMEZ-URIBE; HUNT, 2016, p. 2).

O que a Netflix chama de "sistema de recomendação" é composto não por um, mas por uma coleção de diferentes algoritmos que produzem a experiência audiovisual do usuário e multiplicam cada vez mais o processamento de dados desse usuário e seu modo de estar na plataforma. O conjunto algorítmico da plataforma, embora se proponha ser "pessoal", não trabalha de usuário para usuário, mas sim, a partir do que a empresa chama de "comunidades globais". Desde a expansão da Netflix para 190 países, os engenheiros da empresa perceberam que a recomendação poderia ser mais eficiente se, em vez de levar em conta apenas a nacionalidade dos usuários, eles também criassem um sistema de grupos baseados, principalmente, nos seus "gostos". Dessa forma, se um usuário do Brasil tem 
preferência por gêneros entendidos como ficção cientifica e suspense, seus dados serão analisados em uma espécie de "cluster global", composto por perfis de diferentes nacionalidades semelhantes a ele. Assim, as ações e as avaliações de todo grupo serão relevantes para escolhas selecionadas para esse usuário em específico.

Esse modelo de funcionamento encontra alguns entraves, como a diferença nos catálogos de cada país. Títulos que estão presentes na Netflix dos EUA podem não ser liberados no Brasil, ou não ficarem no catálogo pelo mesmo período de tempo, ou ainda não apresentarem legenda ou dublagem em português (GOMEZ-URIBE, 2016). Por isso, conforme os diretores da empresa, Yves Raimond e Justin Basilico (2016), a fim minimizar os problemas decorrentes disso, "Incorporamos em cada algoritmo a informação que os membros têm acesso a diferentes catálogos com base na geografia e no tempo, por exemplo, com base em conceitos da comunidade estatística sobre como lidar com dados faltantes." (RAIMON; BASILICO, 2016, tradução nossa, doc. não paginado). Desta forma, e de outras que veremos mais adiante, a Netflix coloca no centro da construção de sentido, sobre sua experiência audiovisual, o banco de dados e o algoritmo: além de o que operacionalmente isso significa, há questão de trazer estas ethicidades para a construção da experiência audiovisual.

Sobre a lógica algorítmica da interface e das categorias, conforme Gomez-uribe e Hunt (2016), a forma como cada linha e cada vídeo é distribuída, ao longo da interface, depende de um algoritmo específico, com funções específicas. São pelo menos oito algoritmos distintos que organizam e recomendam produções de um modo particular para o usuário.

O algoritmo chamado "Personalized Video Ranker: PVR" (classificador de vídeo personalizado) atua, como o nome diz, para elencar a ordem dos vídeos distribuídos em categorias clássicas como "Filmes de suspense", de acordo com o que entende ser a preferência de cada usuário. Nesse algoritmo, os sinais personalizados podem ser misturados a dados de popularidade, gerando, por exemplo, a categoria "Populares". Esse algoritmo garante que, mesmo em categorias iguais, usuários diferentes nunca verão os mesmos vídeos ou ordem. Já a categoria "Principais escolhas para fulano" é organizada pelo algoritmo "Top N Video Ranker", que busca em todo o catálogo uma seleção de vídeos que seriam os "melhores" para cada perfil. 0 algoritmo que dá origem a categoria "Continue assistindo" faz uma leitura dos conteúdos seriais ou não seriais em que o usuário parou de rodar antes de finalizar. Nem tudo que o usuário dá play e para entra nessa lista, apenas aquilo que o algoritmo acredita que a chance de ele seguir assistindo ou reassistir são 
grandes. A leitura é feita com base em informações como "o tempo decorrido desde a visualização, o ponto de abandono (meio do programa versus início ou final), se os títulos diferentes foram visualizados e os dispositivos utilizados" (GOMEZ-URIBE; HUNT, 2016, p. 4). 0 algoritmo de similaridade ou "sims" funciona de vídeo por vídeo e é o responsável pela produção das categorias "Porque você assistiu a tal título" ou "Porque você adicionou tal título à sua lista". Este é um algoritmo não pessoal que calcula uma lista de vídeos similares para cada título do catálogo. Não há personalização na seleção dos vídeos, mas sim nas categorias "similares" que aparecem na interface de cada usuário. Esses são alguns dos engendramentos algorítmicos que ocorrem no interior da plataforma, de maneira bem simplificada; afinal, além da construção das categorias, há algoritmos agindo em cada micro informação contida nas páginas.

Há um diálogo entre o usuário, seu percurso e o software que lê esse trajeto e reorganiza os dados produzidos por ele. Dessa maneira, o vídeo (e como ele, a TV, o cinema ou o meio que o produziu) passa a ser ressignificado, como um conjunto de tags que podem ser associadas sempre a novos dados, em novos corredores do grande banco de dados e oferecidos ao usuário pela leitura de seus percursos. Em termos de produção de sentido, está sendo construída uma TV on demand.

\section{A TV on demand e o banco de dados como forma cultural}

Manovich (2006) já alertava como a base de dados configura uma forma presente nas novas mídias e, ao mesmo tempo, representa uma nova maneira de percebermos a nós e ao mundo; por isso, seria uma forma cultural. Basta olhar algumas práticas cotidianas e perceber como, em minutos, acessamos, em uma rede social, imagens sobre o novo emprego do amigo, do lado da notícia sobre a superação da doença da tia do colega de infância e as opiniões de nosso vizinho do prédio sobre a situação política do país. Produzimos dados fotográficos, textuais, audiovisuais - de nosso cotidiano, porque temos os dispositivos para fazê-los, os espaços para compartilhá-los e o porquê tornou-se uma prática cultural ou, como diriam Foucault (1985) e Deleuze (1999), uma urgência do dispositivo contemporâneo. Em consonância, a mania de armazenamento torna-se também parte desse dispositivo, que amplia cada vez mais as formas e as medidas das memórias com seus gigas e terabytes, capazes de conter cada vez mais dados. 
Em janeiro de 1994, no editorial da revista Mediamatic, comentando por Manovich (2006) previa-se que, até o final do século XX, a quantidade total de memória de um computador no mundo seria maior do que a quantidade total de informação. Conforme o autor, a revista chamava a atenção para o fato de armazenar tudo desde a cultura até o DNA, passando por registros de saldos e conversações telefônicas, entre tantas outras coisas. A prática de reunir, de juntar, de conectar, de organizar de alguma forma que facilite o acesso, a manipulabilidade, o uso de dados se evidencia anterior à web. 0 gênero estava presente desde os antigos gabinetes de curiosidades, os museus, as bibliotecas, os álbuns de fotos, as enciclopédias, os dicionários, as agendas e as bibliografias. Antes da web, inclusive, o armazenamento em CD-ROM e em outros meios digitais inspirava novos gêneros de base de dados, como o banco de dados biográficos.

Conforme observamos, uma primeira passagem pelas interfaces da Netflix sugere um banco de dados de produções e de gêneros. Um seriado parece um banco de temporadas; uma temporada, um banco de episódios; o assinante, um conjunto de perfis (até cinco); cada perfil, um banco de preferências; a assinatura, um conjunto de telas simultâneas (até quatro); e o tempo que o assinante está na plataforma, um conjunto de escolhas (de dispositivos, de vídeos, de cliques, de gostei ou não gostei). Dentre os elementos elencados, o usuário é construído ali como o dado-chave e seu percurso como produtor de dados para a construção audiovisual da Netflix. São seus trânsitos e percursos (dentro e fora da plataforma) os que geram dados e os que configuram a sua própria interface e o perfil que a plataforma vai criando do usuário.

Ao pensar a base de dados como forma cultural, Manovich (2006) a percebe como uma prática tão cotidiana que nos leva a ver o mundo dessa forma. Para ele, é na internet onde a forma de base de dados floresceu, com seus blocos de textos, imagens, links e fragmentos, em que sempre é possível - e aparentemente desejável - acrescentar mais um.

Desde o ponto de vista da experiência do usuário, os dados aparecem como coleções de elementos sobre os quais ele pode efetuar diversas operações - olhar, navegar, salvar, copiar, buscar, editar. Por isso, Manovich (2006) pensa, também, como forma cultural, junto ao banco de dados, as "operações" que o software permite: os modos como intervimos nesses dados. Na era do computador, independentemente de trabalhar com dados, texto, imagem vídeo, espaço tridimensional ou uma mistura disso tudo, aplicam-se as mesmas operações básicas - cortar, colar, buscar, compor, filtrar - as quais não só estão incluídas no 
software, como vão muito além dele, e fazem parte do mundo social como formas de trabalhar com dados, mas também de pensar e de existir.

A própria imagem digital abrange um banco de dados, posto que consiste em uma série de camadas, com diversos elementos que podem ser alterados, como trocar o rosto de uma pessoa pelo de outra, substituir o fundo, mudar a cor, dentre outras opções. Então, compreender o banco de dados como forma cultural representa uma experiência de nós mesmos e do mundo como um conjunto sempre aberto à modificações e a remixes, em que a falta de uma parte não compromete o funcionamento do todo, como podia acontecer com objetos industriais, montados em série ou com obras de arte, como a escultura. Portanto, essa outra ontologia também faz com que nos acostumemos melhor com a ideia de processo do que com a ideia do produto (pronto e acabado), inclusive ao refletir sobre o audiovisual ou o vídeo.

\section{0 algoritmo como constructo}

Naquilo que Manovich (2015) chama de ontologia do computador, que passa a ser culturalmente também a ontologia do mundo vista pelo computador, o banco de dados é uma metade. Talvez, a metade mais visível. A outra metade é feita de algoritmo. Um programa recebe dados, executa um algoritmo e produz novos dados. Vimos, claramente,como funciona essa dinâmica nas descrições da plataforma, nas páginas anteriores. 0 algoritmo contempla um conjunto de regras e de procedimentos lógicos para a realização de certa atividade, como uma receita de bolo ou a explicação a alguém sobre como chegar ao aeroporto. Todavia, há diferença entre esses algoritmos e outros tantos que criamos para viver juntos desde os primórdios. Manovich (2005) lembra que um computador digital moderno é capaz de executar milhares de algoritmos ao mesmo tempo, mas que antes da computação, eles eram executados manualmente, ou seja, com esforço humano. 0 autor quer dizer que não há nenhum grande mistério no funcionamento dos algoritmos, ainda que, em geral, eles sejam mascarados por outras camadas do software, em que a parte mais visível é a interface.

Um algoritmo é uma sequência de passos que precisa ser seguida para a realização de uma tarefa. Os computadores digitais permitem executar a maior parte dos algoritmos muito rapidamente, por mais que, em princípio, um algoritmo, já que é apenas um conjunto de passos simples, também possa ser executado por um humano, embora muito mais 
lentamente. Por exemplo, um humano pode colocar arquivos em uma ordem específica, contar um número de palavras em um texto ou recortar parte de uma imagem e cola-la em um lugar diferente. (MANOVICH, 2005, p. 18).

Embora Manovich declare que os algoritmos não são espécies nativas da computação, mas algo inerente ao comportamento humano, ele reconhece que a aceleração na execução desses algoritmos produz fenômenos qualitativamente novos. "Acelerar dramaticamente a execução de um algoritmo de perspectiva torna possível uma técnica de representação anteriormente inexistente: o movimento fluido através de um espaço com perspectiva." (MANOVICH, 2005, p. 19). Isso quer dizer que a transposição computacional do algoritmo possibilita a produção de desenhos digitais em perspectiva ou filmes com recursos gráficos, entre outras coisas, de forma mais ágil e inteiramente feitos por meio do computador. 0 algoritmo passa, assim, a moldurar a produção humana em geral e a audiovisual em particular e se torna um elemento central na tecnocultura digital.

Em diversos espaços, usuários de redes sociais contam como foram banidos pelo algoritmo. Bruno (2006), quando aborda as práticas de rastreio e de constituição de perfis, dá o exemplo da menina de 16 anos, residente nos Estados Unidos, filha de imigrantes muçulmanos, que foi expulsa porque seu perfil apresentava-se como potencial "meninabomba" pelos sites que acessava.

Manovich (2015) pondera que os algoritmos nos jogos geralmente têm uma tarefa bem definida para o jogador executar e ganhar, como dirigir através de obstáculos, matar inimigos, dentre outras. A superfície narrativa de um game - em que você é um astronauta treinado para chegar à lua e eliminar todos os obstáculos que apareçam no seu caminho (mutantes, extraterrestres) - mascara um algoritmo simples que está explícito ao jogador para entrar no jogo. Há um algoritmo que só é conhecido pelo jogador mais engajado, aquele que percebe que sempre que acontecem as condições $\mathrm{x}$ e $\mathrm{y}$, os inimigos aparecerão da esquerda, por exemplo. Assim, o jogador reconstrói uma parte do algoritmo. Sobre essa dimensão do algoritmo, passível de decodificação, Chun reitera:

0 fato de que o código alegadamente produz uma interface pode ser revelado, o fato de que o código fonte existe significa que a verdade está por aí. Conhecer o código é ter uma forma de visão de "raio X" que faça coincidir o interior e o exterior, e o ato de revelar fontes ou conexões se torna um ato crítico por si só (CHUN, 2008, p. 315-316, tradução nossa). 
Essas duas formas culturais - banco de dados e algoritmo - são, então, centrais nos modos em que o mundo está sendo codificado e decodificado (FLUSSER, 2007). Eles moldam nossos modos de ver o mundo e o modo de ver o audiovisual. No caso que nos interessa aqui e, segundo veiculou a reportagem da revista Veja, a Netflix não só armazena dados do acesso de cada usuário, mas também toma decisões a partir deles, como a escolha do ator Kevin Spacey - que interpreta Frank Underwood, na série House Of Cards - feita com base na frequência de acesso e na boa avaliação dos assinantes às produções em que o ator fez parte. A matéria ainda reforçava a aposta "no algoritmo" como ponto alto da rede: "Um dos segredos do sucesso da empresa é a forma eficaz como seus algoritmos - os códigos computadorizados que ordenam, automaticamente, o site e os aplicativos da companhia coletam e tabulam informações dos usuários, sem que eles tenham ciência disso." (THOMAS, 2016, p. 109).

A matéria encerra com uma identificação entre usuário e algoritmo: “Além disso, a estratégia serviu de alicerce para que a Netflix passasse a ouvir sempre o que seus algoritmos têm a dizer antes de divulgar um filme ou uma série." (THOMAS, 2016, p. 109). No mundo codificado por software, os algoritmos gerados pelos dados do usuário e pelo software dão sentido aos usuários.

Usuários passam, assim, a fundamentar o conjunto de seus trânsitos, de seus acessos,por vezes conscientes, por vezes por engano, geralmente movidos pela própria interface. Além da prática operacional cada vez mais própria da internet (rastreio de dados e construção de perfis), há na Netflix uma construção de sentido muito particular e positiva em relação ao algoritmo. 0 algoritmo, uma ethicidade-chave da plataforma, é construído quase como um porta-voz, representante, algo assim como amigo de infância, ou até um advogado do usuário.

Na barra institucional, consta um link "Preferências de cookies". Ali é explicado que a Netflix e seus parceiros utilizam tecnologias para facilitar o acesso: "permitindo-nos reconhecer você a cada vez que você volta, para fornecer e analisar nossos serviços, para aprender mais sobre nossos usuários e seus prováveis interesses e para personalizar e enviar mensagens de marketing ou publicidade" (NETFLIX, 2017). Por isso, a página dedicase a informar o assinante sobre o uso dessas tecnologias. Nesse mesmo texto, explicam-se os três tipos de cookies usados pela empresa. O cookie é moldurado aqui como "alguém" que colabora com o usuário para que tenha acesso facilitado e esteja diante de um mundo mais “amigável". 
Esses cookies teriam na Netflix três formas diversas. Em primeiro lugar, os indispensáveis para acessar o serviço. Em segundo, aqueles que "personalizam e aprimoram a sua experiência online com a Netflix", ajudando a lembrar de preferências e evitando que se precise digitar informações já fornecidas. Por último, são os cookies relacionados à publicidade que "[...] usam informações sobre a sua visita a esse e outros sites, como páginas visitadas, seu uso do serviço ou sua resposta a anúncios e emails, para exibir anúncios mais relevantes a você." (NETFLIX, 2017, doc. não paginadop).

A prática da chamada usabilidade ou "interface amigável" distancia o usuário da linguagem própria do dado e o coloca diante de um mundo de fácil acesso que ele usa independente de entendê-lo ou não. Essa prática vem muitas vezes acompanhada de uma estética "amigável" que Beiguelman $(2010,2011)$ chama de "capitalismo fofinho", ao se referir às grandes empresas "ponto com" como Google, Twitter e Facebook, com suas cores infantis, formas arredondadas e sons onomatopéicos. A autora percebe nessas marcas um imaginário infantilizado que enuncia um mundo feliz, perfeitamente resolvido. Ela está naturalizada como se fosse um valor consensual em que todo usuário quer e precisa deixar os códigos próprios do meio para os entendidos e ficar diante de mundos facilmente manipuláveis, bonitos, coloridos e "seguros", onde possamos andar sem nos preocupar por nada.

A construção do universo de liberdade tão amigável ao usuário é tensionada pelo que Chun (2005) defende como ideologia do software. Em seu entendimento, o software produz "usuários". "As 'escolhas' que os sistemas operacionais oferecem limitam o visível e o invisível, o que se possa imaginar e o inimaginável. Você não está, contudo, ciente do software, da constante construção e interpelação (ou 'uso-amigável')." (CHUN, 2005, p. 43, tradução nossa).

É prática comum de várias empresas "ponto com" e seus softwares, a criação de um ambiente amigável associado a sentidos de conforto, de familiaridade e de ausência de perigo ${ }^{4}$. Pagamos por esses serviços com nossos dados, às vezes, com nosso dinheiro, e sobretudo com a assimilação de determinada construção de imagens e de imaginários sobre o mundo e sobre nós mesmos. Aceitamos parte desse pagamento quando assinamos algo, ao criarmos nosso login, que geralmente está moldurado como "termo de privacidade".

\footnotetext{
${ }^{4}$ Retomando-se aqui o lema do Google - don't be evil - não seja mau, que recentemente passou para seu lado positivo, do the right thing - faça a coisa certa.
} 
"Para o que serve o software se não para o esforço de fazer algo explícito, de fazer algo intangível visível, enquanto que ao mesmo tempo torna o visível (como a máquina) invisível?" (CHUN, 2005, p. 44, tradução nossa). É nisso que reside a ideologia do software, quando se escolhe o que se quer mostrar ou esconder, oferecendo ao usuário uma gama de opções que é sempre limitada, embora o faça crer o contrário. "O poder do software encontra-se nesta dupla ação onde o visível torna invisível, um efeito de linguagens de programação torna-se uma tarefa linguística." (CHUN, 2005, p. 44, tradução nossa). Chun alerta que nenhuma mídia é isenta de intenções e que, por isso, é necessário olhar para elas, não apenas como um artefato tecnológico, mas também ideológico.

\begin{abstract}
Nossas interações com o software têm nos disciplinado, criado certas expectativas sobre causa e efeito, ofereceu-nos prazer e poder que nós acreditamos que deve ser transferido para outros lugares. A noção de software tem penetrado em nosso vocabulário crítico na maioria das vezes sem questionamento (CHUN, 2005, p. 47, tradução nossa).
\end{abstract}

Para Chun (2005, p. 47, tradução nossa), é necessário questionar, olhar além das camadas superficiais do software "para compreender as novas formas em que conhecimento visual está sendo transformado e perpetuado, não simplesmente deslocado ou tornado obsoleto". No entanto, a própria ação da interface de programar o usuário, para aceitar caminhos estabelecidos, e a própria constituição das empresas "ponto com" - inclusive a Netflix - como universos limpos e coloridos em que reina uma paz de laboratório em oposição aos sentidos identitários de outros espaços sociais (como a rua, por exemplo, como lugar de violência e de ameaça) devem ser questionados. Por isso, e em concordância com Chun, considerando-se que o "software produz 'usuários"' (2005, p. 43), questionamos: que usuários e que universos audiovisuais são produzidos na interface criada pelo software Netflix?

\title{
7 Considerações finais
}

A Netflix, a partir de um recorte muito específico feito neste artigo, constrói-se como um grande banco de dados de títulos processado e personalizado por um "simpático" algoritmo. 0 usuário não mais precisa se preocupar, já que "alguém" está tentando entendêlo, segui-lo e resolver sua vida desde a primeira vez que acessa a plataforma. Isso faz parte da "privacidade" construída no site e "concordada" pelo usuário aqui e em tantos outros espaços da rede. Se os cookies não forem suficientes, o usuário tem outro algoritmo, que é a 
barra de busca na qual, ao iniciar a escrita de uma palavra, de imediato, vão aparecendo os títulos desbloqueados e personalizados para ele. De última, se o usuário quer alguma coisa diferente e está com tempo, clicando em "navegar" ou andando pelos corredores de seu perfil, consegue se inteirar acerca de uma série de gêneros (um construto muito próprio da plataforma, ajustado ao usuário) e escolhe ali algo para assistir.

A dinâmica audiovisual do software da Netflix passa por diversas questões, mas a interface, o usuário, os dados e algoritmos que existem entre ambos são fundamentais em termos operacionais, estéticos e ethicos, isto é, em termos de construção de sentido, como infinitos dados a serem combinados "onde, quando e como quiser".

McLuhan e Powers (1993) já compreendiam o banco de dados como a chave da aldeia global em experiência anterior à internet. Para os autores, a aldeia global não se referia à globalização em curso. Ela envolve a dinâmica com que as mídias eletrônicas operam sobre a cultura moderna. A tecnologia do xérox, por exemplo, operava um tipo de movimento de aldeia global sobre o livro, ao converter cada pessoa em seu próprio editor. "Podemos fazer um livro em que as pessoas podem ir adicionando páginas continuamente de outros livros se for necessário." (MCLUHAN; POWERS, 1993, p. 101, tradução nossa).

Benjamin (1986) pensa a metrópole como o espaço em que o dado se multiplica e o fragmento viaja em diversas direções. Para ele, tanto a metrópole como o cinema encontram na montagem o "poder surreal ao fragmento": o de viajar em várias direções e permitir, assim, novas cadeias de significados. Sobre a visão benjaminiana, Canevacci (2001) sinaliza que era o contexto comunicativo urbano que permitia ao autor estabelecer novas cadeias significantes, "Mas, só a grande cidade tem esta estranha liberdade [...]" (CANEVACCI, 2001, p. 101). Foi o dito poder do fragmento que viabilizou ao filósofo "arrancar" as citações de contexto para encontrar novos sentidos, como foi o caso relatado por Canevacci e citado pelo próprio Benjamin, de um aviso de jornal: “Em 1867, um comerciante de tapetes colou cartazes de propaganda nos pilares de uma ponte [...]" (BENJAMIN, 1986, p. 232). 0 aviso, arrancado do contexto, permite a Benjamin ligar uma nova cadeia significante: um tapete, um cartaz, uma ponte.

Esta concatenação produz novas sensibilidades, desorienta as percepções tradicionais e estáveis: um tapete pode recobrir verticalmente uma ponte, sobre a qual estender-se com o olhar ou com a imaginação. Ou então é a ponte quem se apresenta como um enorme tapete sobre o qual passear como um flanêur. Ou ainda a cidade inteira é um cartaz imenso no qual se 
transita indiferentemente entre pontes, tapetes, cisnes, Andrômedas (CANEVACCI, 2001, p. 101).

Algumas questões ficam como perguntas para olhar a plataforma em questão e a forma de construir dados do software nas interfaces contemporâneas. Como a "estranha liberdade", atribuída por Benjamin ao poder surreal do fragmento, está presente nos modos em que a Netflix constrói seus mundos? Há espaço para estas novas sensibilidades que desorientam as percepções tradicionais e estáveis nas "interfaces amigáveis"? O que as relações entre interface, usuário, dado e algoritmo, que constituem a ontologia da web em geral e da Netflix em particular, dizem sobre o audiovisual contemporâneo, suas interfaces e usos? Novas flaneuries e processos desconstrutivos, isto é, novas montagens deverão ser feitas para responder tais questões.

\section{Financiamento}

Coordenação de Aperfeiçoamento de Pessoal de Nível Superior (CAPES) e Conselho Nacional de Desenvolvimento Científico e Tecnológico (CNPq).

\section{Referências}

BEIGUELMAN, Giselle. Piratas: os dissidentes da nova ordem. 2010.

\section{BEIGUELMAN, Giselle. Entre cinema lascado, tecnofagias e outras alternativas ao} "capitalismo fofo". TCAV, 2011.

BENJAMIN, Walter. Obras escolhidas I: magia e técnica, arte e política. São Paulo: Brasiliense, 1986.

BENJAMIN, Walter. Passagens. Belo Horizonte: Editora UFMG, 2006.

BITTENCOURT, Daniel de Andrade. Quando a interface é a mensagem: procedimentos técnico-estéticos como estratégias de diferenciação em portais de informação, uma análise dos portais UOL e Globo.com. 2007. Dissertação (Mestrado em Ciências da Comunicação) Universidade do Vale do Rio dos Sinos, São Leopoldo, 2007.

BRUNO, Fernanda. Dispositivos de vigilância no ciberespaço: duplos digitais e identidades simuladas. Revista Fronteiras: estudos midiáticos, Porto Alegre, v. 8, n. 2, p. 152-159, maio/agosto 2006.

CANEVACCI, Mássimo. Antropologia da comunicação visual. Rio de Janeiro: DP\&A, 2001. 
CARDOSO, Reizel Martins. Webvisualidades televisivas: a remixabilidade profunda em HitRecord on TV. 2016. Dissertação (Mestrado em Ciências da Comunicação) - Universidade do Vale do Rio dos Sinos, São Leopoldo, 2016.

CHUN, Wendy Hui Kyong. On "sourcery," or code as fetish. Configurations, Baltimore, v. 16, n. 3, p. 299-324, 2008.

CHUN, Wendy Hui Kyong. On software, or the persistence of visual knowledge. Grey Room, Massachusetts, n. 18, 2005.

DELEUZE, Gilles. ¿Que és un dispositivo? In: BALIBAR, Etinenne et al. Michel Foucault, filósofo. Barcelona: Gedisa, 1999.

FLUSSER, Vilém. 0 mundo codificado: por uma filosofia da comunicação. São Paulo: Cosac Naif, 2007.

FLUSSER, Vilém. Pós-história: vinte instantâneos e um modo de usar. São Paulo: Duas Cidades, 1983.

FOUCAULT, Michel. Microfísica do Poder. Rio de Janeiro: Grall, 1985.

GOMEZ-URIBE, Carlos A.; HUNT, Neil. The Netflix recommender system: algorithms, business value, and innovation. New York: ACM, 2016.

GOMEZ-URIBE, Carlos. Recomendações: uma abordagem global. Netflix Media Center, Los GatosCidade de publicação, 17. Fev. 2016. Disponível em:

<https://media.netflix.com/pt_br/company-blog/a-global-approach-to-recommendations>. Acesso em: 25 ago. 2018.

KILPP, Suzana. A traição das imagens. Porto Alegre: Entremeios Editora, 2010.

KILPP, Suzana. Ethicidades televisivas. São Leopoldo: Ed.Unisinos, 2003.

MANOVICH, Lev. El lenguaje de los nuevos medios de comunicación: la imagen en la era digital. Buenos Aires: Paidos, 2006.

MANOVICH, Lev. Novas mídias como tecnologia e idéia: dez definições. In: LEÃO, Lúcia (Org.). 0 chip e o caleidoscópio: reflexões sobre as novas mídias. São Paulo: Senac, 2005.

MANOVICH, Lev. O banco de dados. Eco-Pos, Rio de Janeiro, v. 18, n. 1. p. 7-26, abr. 2015.

MCLUHAN, Marshall. POWERS, Bruce. La aldea global. Barcelona: Gedisa, 1993.

MONTAÑO LA CRUZ, Sonia Estela. Plataformas de vídeo: apontamentos para uma ecologia do audiovisual da web na contemporaneidade. 2012. Tese (Doutorado em Ciências da Comunicação) - Curso de Pós-Graduação em Ciências da Comunicação, Universidade do Vale do Rio dos Sinos, São Leopoldo, 2012.

NETFLIX. Centro de ajuda Netflix. O que é a Netflix? [2018?]. Disponível em: $<$ https://help.netflix.com/pt/node/412>. Acesso: 14 set. 2018. 
NETFLIX. [Portal streaming]. 2017. Disponível em: <netflix.com>. Acesso em: 19 set. 2017.

NETFLIX INVESTORS. Long-term view. [2018?]. Disponível em:

<https://www.netflixinvestor.com/ir-overview/long-term-view/default.aspx>. Acesso em: 25 ago. 2018.

RAIMOND, Yves; BASILICO, Justin. Recommending for the world. The Netflix Tech Blog, Los Gatos, 17 fev. 2016. Disponível em: <https://medium.com/netflix-techblog/recommendingfor-the-world-8da8cbcf051b>. Acesso em: 25 ago. 2018.

REDAÇÃO ELLE. The Crown é a série mais cara da história da Netflix e conta a história da Rainha Elizabeth. Assista ao trailer! Elle, São Paulo, 28 out. 2016.

THOMAS, Jennifer Ann. Você vê a Netflix e ela também vê você. VEJA, São Paulo, v. 49, n. 20, p. 108, jun. 2017.

VENTURA, Felipe. Netflix tem impressionantes 76.897 gêneros para classificar filmes. GIZMODO, São Paulo, 3 jan. 2014. Disponível em: <http://gizmodo.uol.com.br/netflixgeneros/>. Acesso em: 18. jun. 2017.

\title{
Software, data and algorithm as cultural forms on Netflix
}

\begin{abstract}
Contemporary audiovisuals - especially those that circulate on video platforms on the web - require looking beyond narratives, as they are embedded in software-mediated environments, becoming both product and producer of algorithm-driven databases. In this article, we intend to understand how databases and algorithms are constituted as cultural forms and, particularly, how they impact the way that Netflix's audiovisual is enunciated. For this, we articulate the framework methodology and the assumptions of authors who approach the media in technocultural perspectives - such as McLuhan, Manovich, Flusser and Chun.
\end{abstract}

\section{Keywords}

Software. Data. Algorithms. Cultural Forms. Netflix. 